\title{
Multiple Dimensions of Mobilization: The Effect of Direct Contact and Political Ads on Latino Turnout in the $\mathbf{2 0 0 0}$ Presidential Election
}

\author{
MATT A. BARRETO \\ University of Washington, Seattle, Washington, USA \\ JENNIFER MEROLLA \\ Claremont Graduate University, Claremont, California, USA \\ VICTORIA DEFRANCESCO SOTO \\ Northwestern University, Evanston, Illinois, USA
}

\begin{abstract}
Campaigns are not national, monolithic, one-size-fits-all events, but instead can be viewed as separate, segmented attempts to engage different groups of voters. This paper explores the effectiveness of different types of mobilization strategies among one group of voters, Latinos. Drawing from an integrated marketing communications framework, we argue that both direct contact and indirect contact should be effective in mobilizing Latinos, with the former having a stronger effect. In addition, we argue that targeted strategies should be more effective than general strategies among this segment of the population. We find support for these hypotheses using data from the 2000 TRPI survey and CMAG data.
\end{abstract}

KEYWORDS campaigns, integrated marketing communications, Latinos, mobilization, Spanish language television advertisements, television advertisements

Each election cycle, campaigns engage in many different strategies to try to mobilize voters to go to the polls. Some of these strategies include airing political advertisements, sending flyers, holding rallies, making calls to people at home, and even paying them a visit at their door. Within each of these

Address correspondence to Matt A. Barreto, Department of Political Science, University of Washington, Box 353530, Gowen 101, Seattle, WA 98195, USA. E-mail: mbarreto@uw.edu 
methods of mobilization, campaigns often try to target their messages to certain groups of voters, who are either considered swing voters or an important demographic group to turnout as part of the party's base. In 2004, pundits talked about the importance of turning out the religious base of the Republican Party, while "security moms" were considered an important swing group. Previous elections also had catchy names for some of the targeted groups, such as "soccer moms," Reagan Democrats, and suburbanites. Campaigns are not national, monolithic, one-size-fits-all, but instead can be viewed as separate, segmented attempts to engage a specific group of voters.

While political science research has examined the effects of general campaign outreach, we are just beginning to understand the relative effectiveness of different types of mobilization strategies. For example, we know that door-to-door canvassing is more effective than calls from phone banks or mailers (Gerber and Green, 2000; Green, Gerber, and Nickerson, 2008). However, there is still a great deal of ground to explore with respect to the effect of different mobilization strategies, especially in conjunction with targeted political communication. In this paper, we ask whether grouptargeted mobilization strategies are effective in increasing voter turnout among that group. Second, we ask whether certain types of strategies, direct contact versus political ads, are more successful agents of mobilization.

Drawing on an integrated marketing communications (IMC) model (e.g., Batra et al., 1996; Kitchen, 2005; Kitchen and Schultz, 1999; Schultz, 1991), we consider how different elements in a political communication mix influence the likelihood of turnout. For the past two decades IMC models have been a staple in the consumer products world and in this paper we utilize this framework to develop hypotheses with respect to a political communications campaign with multiple components. An IMC model specifically considers market segmentation or, in our case, electorate segmentation, in addition to direct and indirect communications. We argue that political advertisements are effective tools of information dissemination; however, unlike more direct methods, ads are not usually as effective in "getting the purchase" or, for our purposes, getting the voter to the polls. Furthermore, messages targeted to a given demographic group may be more effective in increasing the likelihood of turnout among that group, as opposed to generic strategies.

We test these hypotheses using data on Latinos and political advertisements from the 2000 presidential election. This election was the first to employ a large-scale, multi-faceted mobilization strategy among a sub-segment of the American electorate, Latinos. Both Democrats and Republicans undertook political campaigns that aggressively combined targeted direct mobilization and targeted indirect mobilization in the form of television advertisements. Post-election analysis by the Hispanic Voter Project estimated that more than 10 million dollars were spent trying to woo Latino voters in 2000 (Segal, 2003; Subervi-Velez, 2008). Twenty-three unique Spanish-language political advertisements aired over 3,000 times in key battleground states with sizable Latino 
populations. In addition to the air war, both candidates and their surrogates organized sophisticated get-out-the-vote (GOTV) drives using telephone, direct mail, and door-to-door outreach in Latino communities. Through an analysis of voter turnout, we assess the effect of general versus targeted political communication upon the Latino electorate, each via two modes of mobilization, direct and indirect.

The inclusion of advertisements (both targeted and general) in a model is an important improvement in understanding the effects of mobilization campaigns. While campaigns have targeted segments of the population for many years, most extant research has not looked at the effects of targeted direct and indirect mobilization on turnout. In this project we focus on Latinos, the largest minority group in the country. Previous studies of largescale, targeted Latino mobilization have focused mainly on GOTV efforts (e.g., Michelson, 2003; 2005; Pantoja and Woods, 2000; Ramírez, 2002; 2007; Shaw, de la Garza, and Lee, 2000), while less work has looked at political advertisements (e.g., Abrajano, 2010; DeFrancesco Soto and Merolla, 2006). In short, we seek to contribute to an understanding of targeted, multi-faceted mobilization efforts.

\section{MULTIPLE METHODS OF MOBILIZATION}

While a laundry list of factors, such as SES (Campbell et al., 1960; Wolfinger and Rosenstone, 1980), social connectedness (e.g., Beck and Jennings, 1982; Leighley and Vedlitz, 1999), group identity (Miller et al., 1981; Tate, 1993), and institutional factors (e.g., Jackman, 1987; Leighley and Nagler, 1992), have been used to explain turnout, scholars have found that mobilization by elites is an integral factor, especially among those least likely to vote (Leighley, 2001; Rosenstone and Hansen, 1993). The mechanism behind this effect is that mobilization offsets the costs of participation for those lower in SES. In this study, we assess both direct and indirect modes of voter mobilization.

\section{Direct Mobilization Effects}

In their seminal book, Rosenstone and Hansen focus on direct mobilization, which consists of political leaders trying to contact citizens personally to encourage them to take action, which might take the form of direct mail and/or door-to-door canvassing (1993). They argue that these forms of direct contact increase the likelihood of participation by creating opportunities for citizens to participate, reducing the costs of acquiring information on the issues, and of citizen activism through activities such as distributing registration forms.

While Rosenstone and Hansen only analyzed the direct contact measure asked in the National Election Study, other researchers have used field experiments to understand the effects of particular types of direct contact 
strategies. Gosnell was the first to test the effect of mailers on turnout in Chicago by exposing some households to flyers encouraging them to vote, and found a positive effect of mailers (1927). The use of field experimentation to test for the effects of mobilization has increased over the last five years, with scholars studying many different types of direct contact strategies. Overall, studies show small and mixed effects for mailers, phone calls, and e-mails on increasing the likelihood of turnout (Gerber and Green, 2000; 2008; Gerber, Green, and Green, 2003; McNulty, 2005; Nickerson et al., 2006; Ramirez, 2005; Wong, 2005). The most promising form of direct contact seems to be door-to-door canvassing, which has a stronger effect on increasing the likelihood of turnout compared to other methods such as phone banks and mailings, regardless of whether the contact is non-partisan or partisan (Gerber and Green, 2000; Nickerson, Friedrich, and King, 2006).

The results from GOTV field experiments have helped further shape our understanding of voter turnout based on mobilization efforts. With respect to more recent studies, Nickerson uses two innovative approaches to campaigning and finds that human-to-human interactions are still superior to electronic outreach. While he shows that e-mail invites are ineffective in voter registration or turnout (2007a), separately he finds compelling evidence that door-to-door appeals can sway multiple household members, even those not directly exposed, because the household member who received the treatment passes along the treatment information to other potential voters in the home (2008). John and Brannan find further evidence that personal contact increases voter turnout; however, their study in Great Britain also shows that telephone-based GOTV can result in elevated turnout (2008).

In fact, a collection of recent work demonstrates that certain types of phone calls can be effective in increasing turnout. Specifically, Ha and Karlan show that interactive phone calls that engage the voter can increase turnout as compared to what they call standard GOTV scripts (2009). In a similar vein, Nickerson finds that the effectiveness of phone calls depends on the quality of the call being conversational and with pauses, rather than whether the calls are delivered from a professional or volunteer phone bank (2007b). Panagopoulos compares partisan and non-partisan messaging done within the same commercial calling center (2009a). Despite large differences in the amount of money spent by the partisan outfits, he finds no difference in the effectiveness in terms of getting out the vote: partisan and non-partisan messaging are equal when implemented by a professional calling center.

Arceneaux and Nickerson provide a word of caution and remind us that not all voters are equally affected by GOTV appeals, and that different studies use different samples of voters (2009). They argue, and show empirically, that low-propensity voters are the most likely to be mobilized by GOTV efforts in prominent elections; however, high-propensity voters are more likely to be mobilized in less salient elections. In sum, the effectiveness of GOTV efforts must be seen in light of both the variance in outreach techniques and target audiences. 
Within the field of Latino politics, mobilization-based explanations of voting have gained prominence. Due to the comparatively lower levels of education, income, and civic resources, recruitment and mobilization are viewed as necessary components for understanding Latino political participation. Early work relied on indirect measures of mobilization (DeSipio, 1996). For example, Pantoja and Woods examined validated vote records from the Los Angeles County Registrar of Voters and found that Latinos residing in cities targeted by the Southwest Voter Registration and Education Project (SVREP) were considerably more likely to vote in the 1998 election than Latinos who were not targeted by the non-partisan civic group (2000). As with the general literature, scholars have increasingly turned to mobilization field experiments. Studies have demonstrated mixed effects for mailers and phone calls (Michelson, 2005; Michelson, Garcia-Bedolla, and Green, 2007; Ramírez, 2005) ${ }^{1}$ and strong effects for door-to-door canvassing (Michelson, 2003; Ramírez, 2005). Other scholars have relied on public opinion data with a larger sample of Latinos. The evidence suggests that self-reported direct contact is a significant predictor of Latino turnout, especially when contact is by a Latino. It is important to note that a consistent finding within the subfield of Latino turnout has been that co-ethnic appeals are the most effective at turning out the vote. This has been repeatedly demonstrated across years, across different geographies, and different election types (Abrajano et al., 2008; Barreto, 2007; Barreto and Nuño, 2011; Nuño, 2007; Ramírez, 2005; Shaw et al., 2000; but see Michelson, 2005).

\section{Indirect Mobilization}

Indirect mobilization is a second form of mobilization, mainly seen in the form of media advertisements. Ads constitute one of many strategies for mobilization and should be viewed as complimentary to the direct measures of contact treated by other scholars. Political spots are less personal and might be more indirect than traditional measures of mobilization, but they may make up for that loss in the extent of their outreach. While they do not necessarily create the opportunities for citizens to participate or reduce the costs of registering to vote, ads can serve the function of reducing information costs by informing citizens about the political stances and capabilities of the candidates running for office. Ads can also increase the salience of the issues at stake and the relevance of participation.

Empirical work supports the mobilizing effects of advertisements. For example, a recent innovative study using campaign street signs found that precincts with a large number of "Vote Tomorrow" street signs actually had higher voter turnout, suggesting that mass volume can sometimes make up for a personalized appeal (Panagopoulos, 2009b). Other forms of indirect mobilization such as radio ads can also mobilize voters. Panagopoulos and Green found a slight increase in local election turnout in cities exposed to mass GOTV appeals over the radio (2008a). Additional evidence from 
Holbrook and McClurg suggests campaign advertising boosts turnout (2005). Their study of presidential campaign media purchases, coupled with presidential visits by state, showed that such forms of indirect mobilization succeeded in turning out the core or base of the respective campaigns.

Most of the literature on the effects of political ads on turnout has centered on a debate with respect to the tone of the political communication. Some scholars have found that negative advertisements depress turnout, while positive ads increase turnout (e.g., Ansolabehere and Iyengar, 1995; Ansolabehere et al., 1994). The mechanism behind this is that negative ads demobilize the opponent's supporters by decreasing levels of political efficacy. However, other scholars have found that negative ads have no effect or actually increase the likelihood of turnout (Finkel and Geer, 1998; Freedman and Goldstein, 1999; Geer, 2006; Goldstein and Freedman, 2002; Wattenberg and Brians, 1999). Recently, Jackson and Carsey have demonstrated that negative ads, in particular the sheer volume of negative ads, can increase turnout in U.S. Senate elections (2007). The mechanism, outlined by the above scholars, is that negative ads might lead to increased information acquisition since negative messages tend to be weighted more than positive ones. Furthermore, they argue that negative ads might have stronger affective responses, leading individuals to have greater engagement in the election and to feel like their votes are more important. While this debate has occurred at the general level, the effect of the tone of the message on Latinos as a targeted segment is under-explored.

Even less work has questioned whether targeted mobilization in political advertisements is successful. Clinton and Lapinski shifted the focus from the effect of the tone of the advertisement to the content of the advertisement (2004). They convincingly argue that ads attempt to prime voters by activating the predispositions of individuals by catering messages to different segments of the population. For example, a campaign might air an ad about Social Security to activate the predispositions of retired individuals, knowing that this content will not appeal to younger segments of the population. They claim that once these predispositions are activated, individuals are more likely to turn out. Using an experimental design, they found weak effects for the tone of the advertisement, but strong effects for targeting. Similar effects for targeting have been obtained in field experiments. For example, Green and Vavreck found evidence that Rock the Vote ads had a mobilizing effect among the target audience, young voters, and null effects among older voters (2008; reported as well in Gerber and Green, 2008).

With respect to Latinos, a field experiment by Panagopoulos and Green found that radio ads on Spanish language stations boosted turnout among those with Spanish surnames in uncompetitive districts in the 2006 congressional election, but had no effect among those without Spanish surnames (2008b; also reported in Gerber and Green, 2008). Elsewhere, a recent field experiment in Queens, New York showed that English language ads were more effective than Spanish language ads in mobilizing Latino 
voters in a special election for city council (Abrajano and Panagopoulos, 2009). On the television advertising front, the work of Federico Subervi Velez and his colleagues has shown that over the last three decades both Republicans and Democrats have formulated Latino-targeted television advertisements (2008). The extent of these targeting efforts have varied both across time and parties, but the 2000 presidential election marked a watershed in terms of the resources and emphasis placed on Latino targeting by both parties. Recent research also highlights the variance in Latino-targeted television appeals. In an analysis of the 2000 presidential election, Abrajano (2010) showed that Latino-targeted advertisements fell into two main categories of policy and non-policy content. The effectiveness of these two types of ads on Latino vote choice depended on the individual's level of acculturation: character-centered Spanish language ads were more effective among less acculturated Latinos. DeFrancesco Soto and Merolla found similar effects for targeted political advertisements, with Spanish language advertisements having stronger effects on the likelihood of turnout compared to general ad appeals for Spanish-dominant individuals (2006).

\section{Multiple Modes of Communication}

Most studies of direct mobilization on Latinos do not consider the effects of indirect mobilization in the form of political ads. This omission is understandable in that it is often difficult to obtain data on the airing of political ads. While some of the more general literature on political advertising include a control for direct contact (e.g., Freedman and Goldstein, 1999; Goldstein and Freedman, 2002), they often do not consider targeted direct contact or some potential problems with contact, such as endogeneity (Rosenstone and Hansen, 1993; Gerber and Green, 2000).

During real campaigns, voters who report direct mobilization are likely to also be exposed to large-scale mobilization attempts via television ads. Furthermore, voters are also exposed to a mix of targeted and more general messages, especially with respect to political advertisements. It could be that when both direct and indirect mobilization variables are included in the model and are differentiated by their level of targeting, only certain strategies really explain the probability of turnout, suggesting that models that only focus on direct contact or indirect contact are under-specified. To develop hypotheses about mobilization via a mixed political communications campaign we turn to an integrated marketing communications model.

\section{INTEGRATED MARKETING COMMUNICATIONS (IMC)}

An integrated marketing communications (IMC) model combines different elements of communication into a unified campaign (Batra, Myers, and 
Aaker, 1996; Kitchen, 2005; Kitchen and Schultz, 1999; Shultz, 1991). It is a very simple framework that is based on having different communication strategies, such as direct contact and advertising, being used in coordination to promote a core message. An IMC sees the different communication elements working in such a way that they are not redundant, but instead the strengths and weaknesses of the different elements are used to offset one another. The concept of developing an IMC strategy emerged in the early 1980s as a result of three principal factors. First, a more competitive and riskier marketplace demanded that the consumer's needs be more successfully addressed. Second, the rapid growth of the technology industry provided additional venues and methods for communications outreach. Last, a diversification on the side of the consumer in terms of lifestyle and tastes made them less receptive to homogenous messages (Kim, Han, and Schultz, 2004; Kitchen, 2005). Prior to the development of this approach, marketing tended to focus on different strategies separately. An IMC approach, in contrast, is a crossfunctional approach.

An IMC strategy relies on multiple (and integrated) communication strategies. However, there are two broad categories of communication: direct and indirect (Batra, Myers, and Aaker, 1996). Direct communication is based on personal contact where more complex information can be conveyed and messages can be better tailored to the recipient. This type of communication can be very persuasive because of the quality of information conveyed. In consumer marketing, direct contact, in contrast to indirect contact, is what creates the final push or "seals the deal." Since direct contact can be tailored to each individual, this strategy should have a stronger effect than indirect contact.

The limitation of this strategy is that it is costly to directly communicate with all potential consumers. The strength of indirect communication lies more in the quantity rather than quality of the communication. Per capita, advertisements are a cost-effective way to reach individuals. Complex visual and emotional devices are also used to increase the persuasiveness of the message.

In addition to understanding the effects of direct and indirect political communications, we also need to consider the effect of segmented versus general communication as part of the communications mix within an IMC framework. Both direct and indirect forms of communication can be used for either a general audience or a very specific group. A segmented, or targeted, strategy develops communications that address the specific needs and concerns of a particular group (Batra, Myers, and Aakers, 1996). Once a segment within the population is identified, messages can be better catered to that target. Furthermore, in the face of modern-day communication clutter (TV, internet, cell phones), it is increasingly difficult to win the attention of consumers, making it even more important to appeal to particular groups. Thus, we should find that segmented, or targeted, communication 
is more effective than general communication strategies given the increased likelihood that a group-tailored message will be attended to and comprehended (Batra, Myers, and Aakers, 1996).

The IMC strategy is a powerful communications approach which can help political scientists better understand the electoral effects of diverse methods of mobilization seen in modern day political campaigns. With respect to voter mobilization, there is one core message: "Get to the polls!" In general, we would expect that mobilization strategies have a significant effect on increasing the likelihood of turnout (H1). However, not all strategies will have the same level of effectiveness. Campaigns use two broad strategies of communication, direct and indirect, to try to get voters to the polls. According to the IMC framework, direct communication should prove more effective than indirect communication. Thus, we should find that direct contact is more effective than indirect contact, in the form of political advertisements (H2). This expectation also fits in well with the field studies on mobilization in which more impersonal methods, such as pre-recorded calls, have weaker effects than door-to-door canvassing (Gerber and Green, 2008). Furthermore, the content of the communication is also important. According to the IMC framework, we should expect that segmented communication is more effective than non-segmented communication (H3). This expectation also fits in well with the literature in political science and psychology, which finds that messages that are tailored to a particular group are more likely to receive attention and cognitively be processed more carefully (e.g., Clinton and Lapinski, 2004; Fiske and Taylor, 1991; Petty and Cacioppo, 1986). As we apply this framework to political messages, it is important to take into account another feature of content, the tone of the message. Since the findings with respect to the tone of advertisements are mixed, we remain agnostic as to whether positive or negative ads increase the likelihood of turnout for Latino citizens.

\section{ELECTION AS A TEST CASE}

Looking at efforts to mobilize Latinos in the 2000 presidential election serves as an excellent test case for our hypotheses. First, both partisan campaigns (and nonpartisan groups) used direct and indirect forms of mobilization. More importantly, both campaigns used a segmented strategy for each type of mobilization, and it is relatively straightforward to identify these segmented strategies. For example, advertisements aired in Spanish are clearly targeted to the Latino population. Furthermore, direct contact by a Latino can be considered a type of targeted communication. Before we turn to the data used to test our hypotheses among Latinos in the 2000 election, we provide some background on the Latino outreach efforts by the major parties.

In 2000, Latino political mobilization came from five major sources: the Bush-Cheney campaign, the Republican National Committee (RNC), 
the Gore-Lieberman campaign, the Democratic National Committee (DNC), and Latino civic organizations. The bigger investors in Latino outreach were Bush and the RNC, outspending Gore and the DNC by a 3-to-1 margin throughout the campaign (Segal, 2003).

Bush was hopeful that he could make inroads with the Latino community, and retained prominent San Antonio media consultant Lionel Sosa to produce his Spanish language advertisements. Sosa advised Bush to invest heavily in television, and to run spots repeatedly in key markets such as Miami/Ft. Lauderdale, Orlando, and Tampa in an effort to reverse gains made by Clinton-Gore with Florida Latinos in 1996. According to Sosa, chief Bush strategist Karl Rove was a strong supporter of aggressively courting the Latino vote, "Rove made the campaign's Spanish-language media plan a top priority both in public and private strategy sessions. During Bush's two Texas gubernatorial campaigns, Rove had seen the positive ways Hispanic voters reacted to his candidacy for Governor" (Segal, 2003: 16).

According to Segal, who interviewed top campaign officials for both Bush and Gore, the Democratic strategy did not make the Latino vote a priority. Instead, the Latino outreach efforts were subsumed as a part of the larger strategy to incorporate and mobilize minorities and other "groups" of voters. This is not to suggest that the Democrats had less concern for Latinos; rather, they did not initiate as aggressive a stand-alone campaign to mobilize Latino citizens. Segal concludes that Democratic Latino outreach "was clearly not treated as the same level of priority as it was in the Bush campaign structure" (2003: 17). However, Gore and the DNC did run a considerable number of Spanish language advertisements. Democrats concentrated their Spanish ads in the Chicago and Los Angeles areas, but were far outpaced in the battleground state of Florida. For example, the Miami market saw Spanish-language Republican ads 302 times, compared to only 14 Spanish-language Democratic ads.

It is important to keep in mind that the 2000 presidential election represented the first full-fledged outreach and targeted mobilization of Latino voters by both major political parties, and their strategies had not yet proven successful. As demographers and political consultants woke up to the realities of the Latino electorate, the candidates and their campaigns were thrust into the world of "amigo" politics overnight, trying to garner the friendship and support of Latino voters without fully understanding the Latino community. Because of this, we should remain open to the possibility that the segmented mobilization in 2000 did not turn out voters as the campaigns probably expected.

\section{DATA AND METHODOLOGY}

Using individual-level data from the Tomás Rivera Policy Institute (TRPI) 2001 post-election survey, merged with market-level data on political ads, we test the effect of direct contact and political ads, differentiated by targeting, on the 
likelihood of Latino turnout. The TRPI survey interviewed 2,131 Latino registered voters in five states: California, Florida, Illinois, New York, and Texas, which accounted for 75 percent of all Latino votes cast in 2000. The post-election survey was conducted between February and April 2001, and validated each respondent's vote history with records from the relevant county election office. Validated vote records are important for research on Latino politics, given Shaw, de la Garza, and Lee's (2000) finding that as many as 20 percent of Latino registrants over-claim voting in a presidential election. The second dataset we use is the Campaign Media Analysis Group (CMAG) 2000 presidential election political advertisement archive. ${ }^{2}$ This resource provides counts of the Spanish- and English-language advertisements, and the tone of each, in the top 75 media markets in the United States. We combine the two datasets, the individual level TRPI survey and the market level CMAG advertisement data, at the zip code level in line with extant studies (e.g., Goldstein and Freedman, 2002; Freedman and Goldstein,1999; DeFrancesco Soto and Merolla, 2006). While our survey respondents are only in five states, they represent the five largest Latino population states, and provide a good range in exposure to political advertisements. Our final data contain ad impressions ranging from zero (Houston) to 8,457 (Miami).

In the CMAG dataset, we separated the ads by their language (Spanish or English) and by their tone (positive, negative, and mixed). We then collapsed the data by the total number of times each type of ad aired in each market and merged this information to the individual level data. ${ }^{3}$ For Spanish ads, not many negative or mixed Spanish ads were aired and we combined the two measures for our analyses. The key independent variables for indirect mobilization are: Positive Spanish, Negative/Mixed Spanish, Positive General, Negative General, and Mixed General. The Spanish ads are indicators of "segmented" ads, which are needed to test the segmentation hypothesis, while the general ads refer to all other ads aired in English. To refresh, we expect that the segmented ads will have stronger substantive effects than the general ads. The literature is mixed with respect to tone: positive and negative ads may have mobilizing effects. Because the television viewing habits of individuals are not uniform, we treat the measure of ads aired in a market as an indicator of maximum exposure opportunity. ${ }^{4}$ If we had information on the television viewing habits of individuals in the survey, we could have developed a measure of television exposure to interact with the total number of advertisements, similar to the method followed by Freedman and Goldstein (1999, 2002). ${ }^{5}$ Without a perfect indicator of exposure, our ad measures likely contain measurement error, which should bias our findings toward null results (Gujarati, 2003: 527). If we find effects even with these imperfect measures, we can be fairly confident that we would obtain the same or stronger results with a better measure of exposure to ads.

From descriptive data from other surveys, it is likely that a fairly high proportion of Latinos are exposed to advertisements that air during news 
broadcasts. In the Latino National Survey, 62.5 percent of the sample indicated watching television news daily, while only 7.8 percent indicated watching television news almost never. In a report by the Pew Hispanic Center, Latinos in a 2004 survey were asked to think about a typical weekday and whether they get their news from various sources. A high proportion reported getting news from national network programs (88 percent), and local news programs (82 percent), compared to newspapers ( 52 percent), the radio ( 58 percent), and the internet ( 29 percent).

The second mode of mobilization, direct contact, is measured at the individual level from the TRPI survey data. Respondents were asked, "Over the past year, were you asked to register or vote by a candidate for office or a person working for a candidate, a representative of a political party, or someone in your community?" If the respondent said yes, follow-up questions were asked to determine whether the contact was by Democrats, Republicans, or a civic group, and whether or not a Latino contacted them. ${ }^{6}$ We created two dummy variables, one for contact by a Latino and one for contact by a non-Latino (no contact serves as the baseline). According to the segmentation hypothesis, we expect that contact by a Latino will have a stronger effect than contact by a non-Latino. Furthermore, the effects of direct contact should be greater than the effects of advertisements. These types of self-reported measures may contain measurement error since individuals will not necessarily recall if they were contacted during the election or may misrepresent if they were contacted. Vavreck's study of self-report bias suggests that, in her sample, mostly white young voters tend to exaggerate their exposure to ads and their actual turnout, which inflates the estimated effects of the ads (2007). This measure of exposure is therefore not as clean as measures used in field experiments; however, they are the only available ones in opinion surveys and have been employed by many scholars (e.g., Nuño, 2007; Rosenstone and Hansen, 1993; Shaw, de la Garza, and Lee, 2000; Verba, Schlozman and Brady, 1995). If our self-reported direct contact measures inflate the estimated effects on turnout while the ad measures deflate the estimated effects, then it stacks the deck a bit more in favor of finding support for our second hypothesis. We should thus interpret the findings with some caution. The direct contact measures, along with the ad measures, are summarized in Table 1.

We also include a series of controls for age, education, income, church attendance, national origin, campaign interest, political efficacy, Spanish media usage, strength of party identification, and those who are married and foreign born. Education, Age, and Income are coded such that higher values indicate higher levels of each. Campaign Interest and Efficacy are both four-point scales where higher values represent greater interest and efficacy, respectively. Spanish Media is also coded on a four-point scale where higher values indicate a greater reliance on Spanish media for information on the election. Partisan strength is measured as either absent, weak, or strong, along a three-point scale. The remaining variables are dummy variables where a one 
TABLE 1 Distribution of Contact and Ads

\begin{tabular}{lccccc}
\hline & & & & & Market With \\
Ad Type & Mean & $\begin{array}{c}\text { Std. } \\
\text { Dev. }\end{array}$ & Minimum & Maximum & $\begin{array}{c}\text { Number of Ads } \\
\text { Ne Maximum }\end{array}$ \\
\hline Non-Latino Contact & .125 & .330 & 0 & 1 & \\
Latino Contact & .189 & .391 & 0 & 1 & \\
Positive Spanish & 101 & 115 & 0 & 292 & Los Angeles \\
Negative/Mixed Spanish & 31 & 38 & 0 & 107 & Miami-Fort Lauderdale \\
Positive General & 849 & 862 & 0 & 2113 & Tampa-St. Petersburg \\
Negative General & 595 & 879 & 0 & 2375 & Miami-Fort Lauderdale \\
Mixed General & 672 & 863 & 0 & 2387 & Miami-Fort Lauderdale \\
\hline
\end{tabular}

indicates being married and foreign born. ${ }^{7,8}$ Finally, we generated the following dummy variables to control for ethnicity: Mexican, Puerto Rican, Cuban, and Other Hispanic.

\section{THE RESULTS}

\section{Testing Direct Mobilization}

We first turn to our test of the effect of direct contact on turnout. Our dependent variable is validated turnout, where a one indicates that the respondent did vote, and zero that the person did not vote. Given that the dependent variable is dichotomous, we use probit analysis. Our key independent variables include the two contact measures, as well as the control variables. The results are presented in the first column (Model 1) of Table 2.

Overall, the model performs well, with 81.24 percent of the cases correctly classified. Most notably, the variable Latino Contact is positive and significant while Non-Latino Contact has no significant effect on the likelihood of turnout. ${ }^{9}$ This finding supports our hypothesis that more segmented communications strategies will be more effective, since the message is more tailored to the individual. This finding is also consistent with Shaw et al.'s analysis of the 1996 election and reveals a trend whereby Latino voters respond positively to co-ethnic direct contact, while non-co-ethnic direct contact has no effect (2000; but see Michelson, 2005, who finds significant effects for co-ethnic and non-co-ethnic contact). Similarly, Nuño's research on Latino electoral behavior suggests that due to issues of trust, prior discrimination, and a sense of community, who delivers the message can be more important than the message itself, and our findings seem to confirm his "messenger" theory (2007).

Many of the controls are significant and in the expected direction. As individuals increase in age, education, church attendance, strength of partisan identification, and campaign interest, they become more likely to turn out. In contrast, Mexican and Puerto Rican origin Latinos and those who primarily get their news from Spanish media are less likely to turn out. 
TABLE 2 Predictors of Latino Voter Turnout, 2000 Presidential Election

\begin{tabular}{|c|c|c|c|c|}
\hline & \multicolumn{2}{|c|}{ Model 1: Contact } & \multicolumn{2}{|c|}{ Model 2: Contact +Ads } \\
\hline & Coef. & S.E. & Coef. & S.E. \\
\hline Non-Latino Contact & -0.028 & $(0.107)$ & -0.038 & $(0.108)$ \\
\hline Latino Contact & $0.140^{*}$ & $(0.097)$ & $0.130^{*}$ & $(0.098)$ \\
\hline Positive Spanish Ad & & & $0.004^{* * *}$ & $(0.001)$ \\
\hline Neg/Mixed Spanish Ad & - & & $-0.015^{* * *}$ & $(0.004)$ \\
\hline Positive General Ad & & & $0.001^{* * *}$ & $(0.000)$ \\
\hline Negative General Ad & & & $0.002^{* * *}$ & $(0.001)$ \\
\hline Mixed General Ad & - & & $-0.002^{* * *}$ & $(0.001)$ \\
\hline Age & $0.013^{* * *}$ & $(0.003)$ & $0.013^{* * *}$ & $(0.003)$ \\
\hline Education & $0.027^{* * *}$ & $(0.010)$ & $0.027^{* * *}$ & $(0.010)$ \\
\hline Income & 0.017 & $(0.022)$ & 0.012 & $(0.022)$ \\
\hline Married & 0.120 & $(0.077)$ & 0.108 & $(0.077)$ \\
\hline Church Attendance & $0.040^{* *}$ & $(0.022)$ & $0.040^{* *}$ & $(0.022)$ \\
\hline Foreign Born & 0.087 & $(0.087)$ & 0.08 & $(0.088)$ \\
\hline Mexican & $-0.202^{* * *}$ & $(0.095)$ & $-0.242^{* * *}$ & $(0.103)$ \\
\hline Puerto Rican & $-0.260^{* * *}$ & $(0.110)$ & $-0.230^{* * *}$ & $(0.112)$ \\
\hline Cuban & -0.068 & $(0.135)$ & -0.196 & $(0.158)$ \\
\hline Spanish Media Exposure & $-0.168^{* *}$ & $(0.090)$ & $-0.169^{* *}$ & $(0.090)$ \\
\hline Campaign Interest & $0.174^{* * *}$ & $(0.045)$ & $0.174^{* * *}$ & $(0.045)$ \\
\hline Political Efficacy & -0.016 & $(0.025)$ & -0.015 & $(0.025)$ \\
\hline Strength of Party Identification & $0.249^{* * *}$ & $(0.047)$ & $0.250^{* * *}$ & $(0.047)$ \\
\hline Constant & $-1.068^{* * *}$ & $(0.280)$ & $-1.136^{* * *}$ & $(0.282)$ \\
\hline $\mathrm{N}$ & 1,738 & & 1,738 & \\
\hline Wald Chi-squared & 122.67 & & 147.16 & \\
\hline Prob $>$ Chi-squared & 0.00 & & 0.00 & \\
\hline Pseudo R-squared & 0.079 & & 0.086 & \\
\hline Percent Correctly Predicted & $81.39 \%$ & & $81.36 \%$ & \\
\hline
\end{tabular}

Note. ${ }^{* * *}$ significant at $\mathrm{p}<.05$ (two-tailed); ${ }^{* *}$ significant at $\mathrm{p}<.10$ (two-tailed); ${ }^{*}$ significant at $\mathrm{p}<.10$, one-tailed test.

The first set of results are consistent with previous research on Latino voting behavior as well as our own hypotheses related to contact and market segmentation. However, there is more to mobilization than just direct contact, and existing models may be underspecified. Specifically, we are talking about the role of indirect mobilization in the form of campaign advertisements, which we incorporate into our second analysis.

\section{Incorporating Indirect Mobilization}

The second column in Table 2 presents the results from a model with all of the variables from the previous analysis and the five measures of political ads that aired in each respondent's media market ${ }^{10}$ : Positive Spanish, Positive General, Negative/Mixed Spanish, Negative General, and Mixed General. ${ }^{11}$ Overall, the model performance is improved relative to the first model, with 81.36 percent of the cases correctly predicted. While this may appear to be a modest improvement, the inclusion of the ad measures does pass a likelihood ratio test $(\mathrm{p}=0.034) .{ }^{12}$ The direct contact measures look similar to model 1 with 
Non-Latino Contact having no effect and Latino Contact demonstrating a positive and significant effect on turnout.

Turning to the effects of the Spanish-language ads, we find a positive, significant effect for Positive Spanish ads and a negative, significant effect for Negative/Mixed Spanish ads. All three general ads are also significant, where positive and negative ads exert mobilizing effects, and only mixed ads exert a demobilizing effect. The results for positive ads support work by Ansolabehere and Iyengar in that they exert a mobilizing effect (1995). Furthermore, the results for negative general ads are consistent with work that argues that they can be mobilizing (e.g., Freedman and Goldstein, 1999; Geer, 2006; Goldstein and Freedman, 2002; Wattenberg and Brians, 1999). However, the negative sign on the Negative/Mixed Spanish ads and Mixed General ads measures is a bit curious. For the latter, it may be that mixed ads increase ambivalence, which in turn depresses turnout. For the former, it could also reflect the sparse number of negative/mixed ads aired in Spanish.

The results from models 1 and 2 suggest that different components of an IMC, direct contact and political ads, are at work in influencing Latino turnout. $^{13}$ In order to test whether direct contact is more effective than indirect contact $(\mathrm{H} 2)$ and whether targeted strategies are more effective (H3), we need to look at the substantive effects of contact and ads on a similar scale.

Since probit coefficients are not directly interpretable, we calculate the first differences using Clarify. We compare the substantive effects of the significant contact and ad measures moving from 0 to 1 (being contacted and one ad aired in the market). The results are reported in Figure 1. The graph clearly illustrates that direct contact has a larger effect on the likelihood of turnout than indirect contact, in support of $\mathrm{H} 2$. However, the effects are only significant for direct contact by a Latino. This finding is supportive of $\mathrm{H} 3$, in that only the segmented direct communication is more effective. We should interpret these results with some caution in that the self-reported measures of contact may slightly inflate the effects, though the fact that we only observe significant effects for Latino contact suggests that there is more than measurement error going on.

Since it is a bit difficult to see the size of the substantive effects of the ads from Figure 1, we generate a figure without the effects for direct contact and report those in Figure 2. This figure reports changes in the probability of turnout, given a one unit increase in the number of ads aired in a market. We get fairly clear support for the segmentation hypothesis (H3) in that the size of the substantive effect for both Spanish ads (regardless of direction) is greater than it is for the general ads. The likelihood of turnout increases 0.1 percent with a one-unit increase in positive Spanish ads, and decreases 0.2 percent for a one-unit increase in Negative/Mixed Spanish ads. The comparable effects for the general ads are weaker, with an increase of 0.008 percent for Positive General ads, an increase of .07 percent for Negative General ads, and a decrease of 0.08 percent for Mixed General ads. 


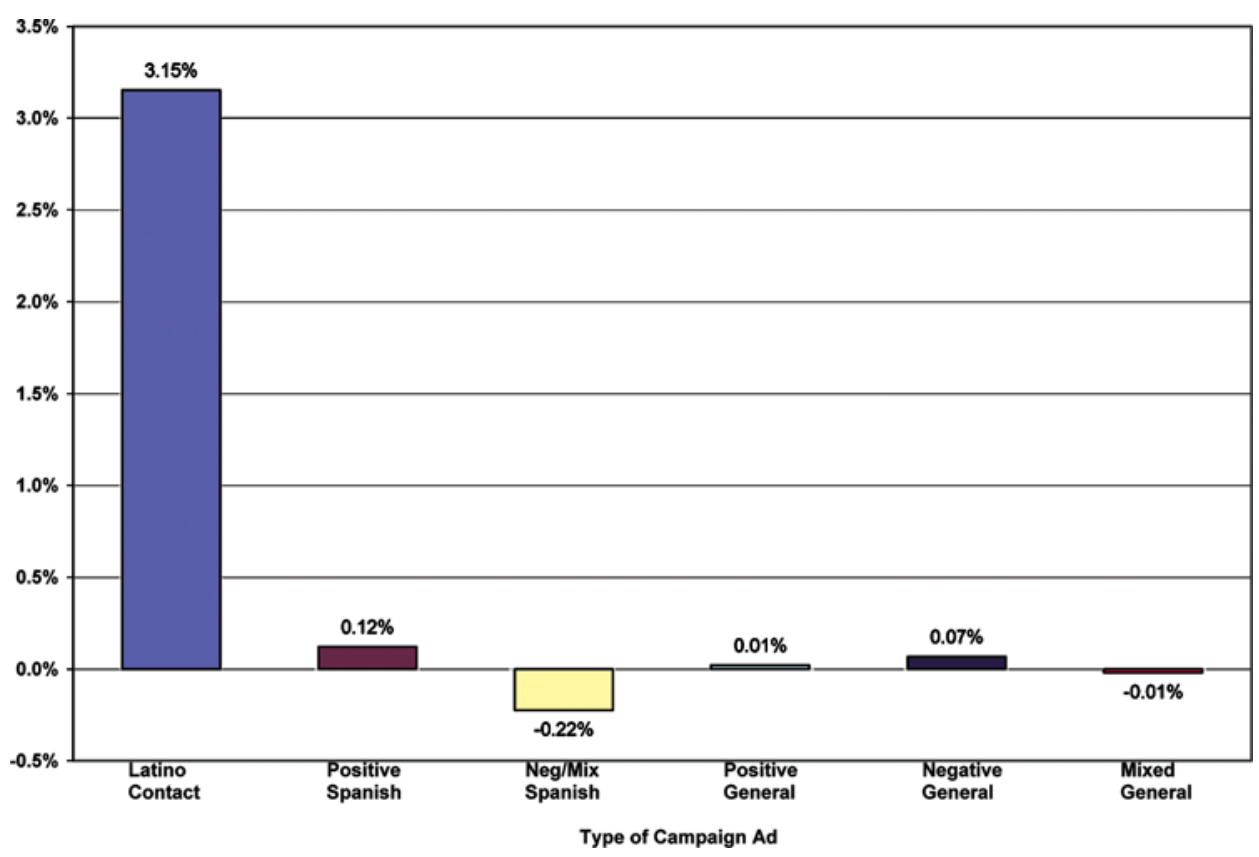

FIGURE 1 Change in the probability of turnout, given a one-unit change in the variable. (Color figure available online.)

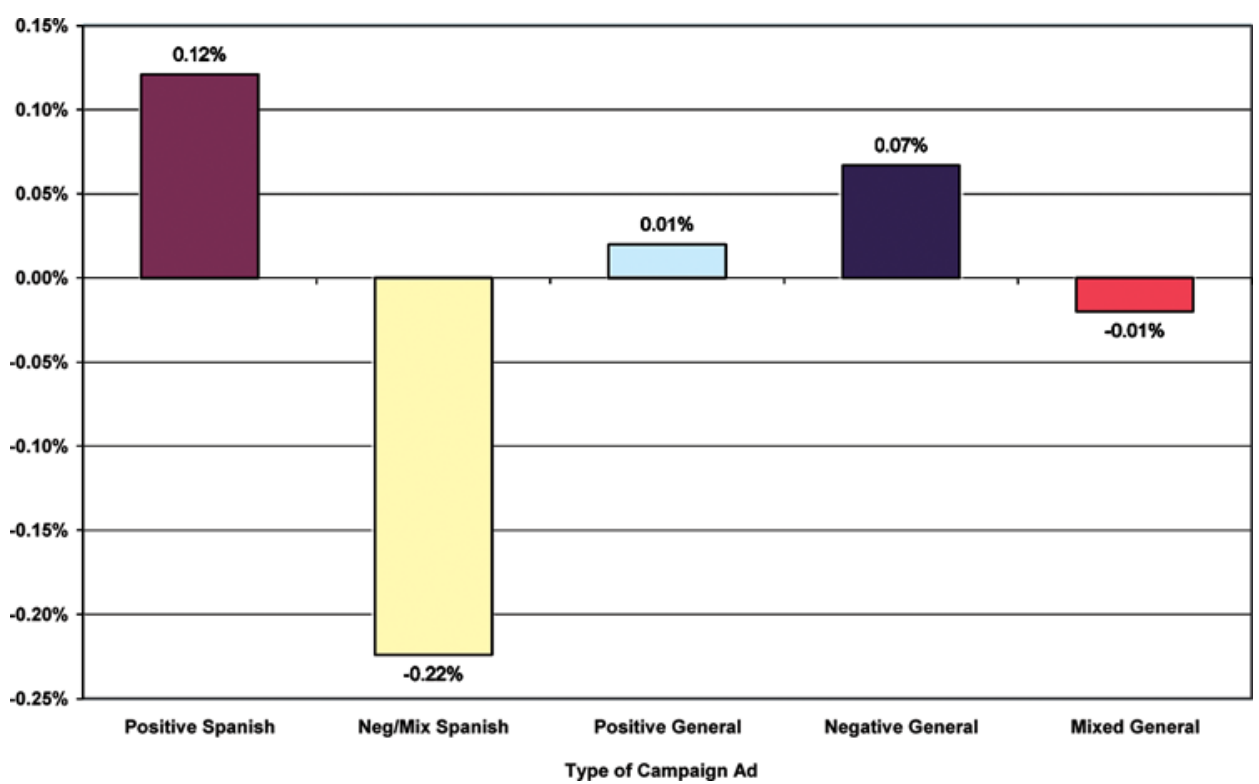

FIGURE 2 Change in the probability of turnout, given a one-unit change in the ad measures. (Color figure available online.) 
Even though the effect of a one unit change is very different for Spanish and General ads, it is very rare that candidates air only one ad, or that a voter will be exposed to only one ad. To gauge the effect of repeated exposure to ads, we plotted the change in the probability of turnout at various levels of the ad measures (for just the ads that exert a positive effect) in Figure 3. While the airing of just one campaign ad does not have much of a mobilizing effect, we find that repeated airings greatly increase the likelihood of voting. In fact, the effect of positive Spanish ads equals the mobilizing effect of direct Latino contact once 27 of these ads are aired in a market. ${ }^{14}$ As more ads are aired and consumed, this form of indirect contact may surpass direct contact in its effect on Latino turnout. In contrast, positive General ads have a very limited mobilizing effect, even after repeated exposure. It would take an estimated 450 positive General ads to equal the effect of 27 positive Spanish ads and contact by a Latino. However, one thing to keep in mind is that our measure of direct contact is blunt. Registered voters were asked whether or not they had been contacted, not necessarily how many times. This measure might also have error since individuals may not have recalled being contacted. In field experiments, which provide a clear measure of exposure, Ramirez and Michelson, Garcia-Bedolla, and Green have found that Latino voters who receive multiple forms and iterations of direct contact are even more likely to vote $(2005 ; 2007)$.

Finally, we also looked at what might happen in some real media markets if we shift the number of ads that aired in a market (we hold the contact

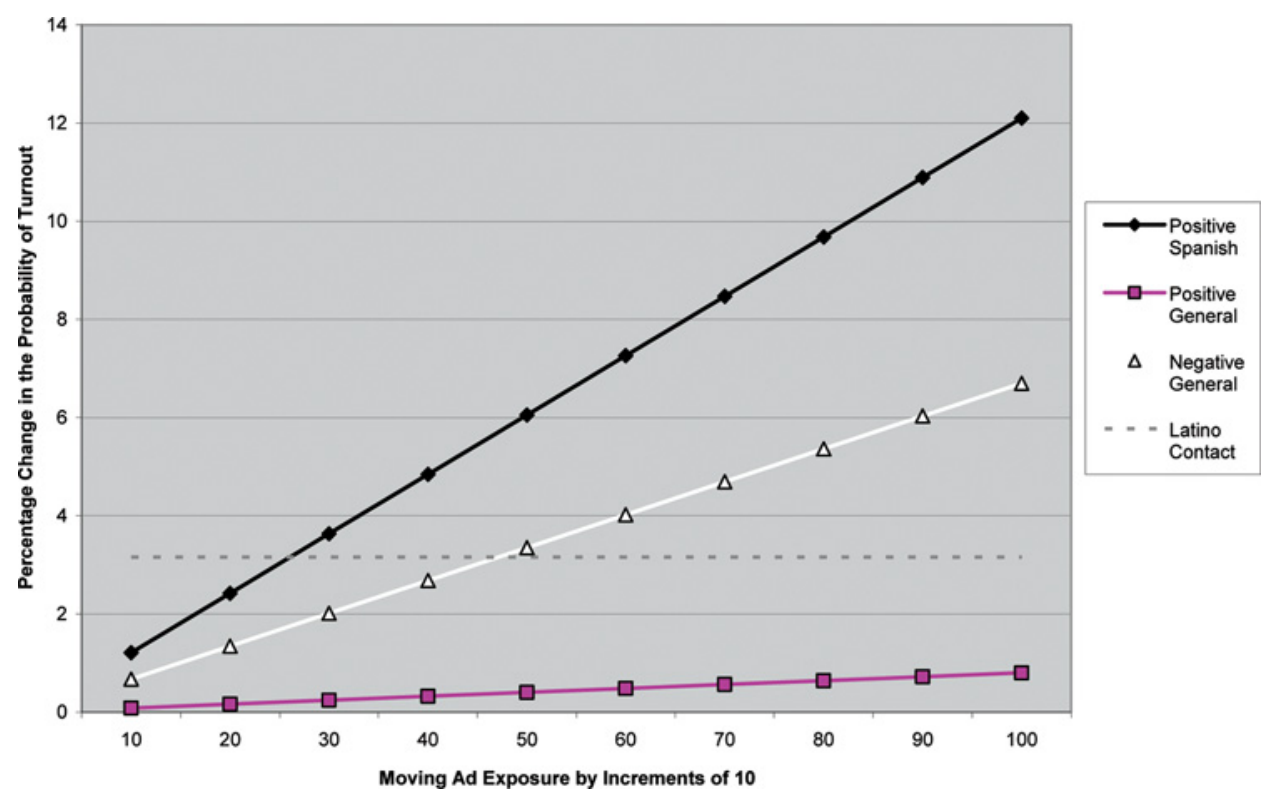

FIGURE 3 Change in probability of turnout across increased exposure to campaign ads. (Color figure available online.) 
measures at zero). We look at four cases: markets that were not exposed to any ads; markets with a high number of targeted but a low number of general ads; markets with a high number of general ads and low number of targeted ads; and markets with high numbers of both types of ads.

We first turn to those markets not exposed to any ads, such as Austin, Dallas, and Houston. If we set our model to have zero ads of each type, we find that the probability of Latino turnout is about 77.5 percent. Recall that this is validated turnout. Furthermore, the baseline is high given our sample of registered voters. If we expose these markets to the mean number of all of the ads, then the probability of turnout jumps to 82.1 percent. However, if we only expose these markets to the mean number of ads that have a positive effect on turnout (positive Spanish, positive general, negative general), then the probability of turnout is $\mathbf{9 7 . 4}$ percent. Thus, the airing of ads that have a positive effect on turnout can greatly increase Latino turnout above what it would be without ads. The trick, of course, is knowing which ads work and which ads do not.

Next, we turn to markets with a high number of Spanish ads and low levels of general ads. There were two markets that fit this category: Los Angeles and San Diego. If we hold the ads at the given values in the Los Angeles market, the probability of turnout among Latinos is 83.8 percent, which is higher than markets not exposed to ads. If we take away the Spanish ads from this market, then the probability of turnout drops to 71.9 percent. Thus, the Spanish ads play an important role in increasing the probability of turnout in this context. If we remove the ads that have a demobilizing effect, then the probability of turnout in this type of market is much higher at 98.3 percent.

There were more markets that had zero or a low number of targeted ads but a high number of general ads, such as Tampa, West Palm Beach, San Francisco, and Chicago. If we hold the ad measures to the values in Tampa (0 target ads, 2113 positive general, 2052 negative general, and 1897 mixed general), the probability of turnout is 97.9 percent. The probability does not change much if we change the number of positive Spanish ads, since the sheer number of general ads is already quite high.

Finally, we examine a market with a high number of both types of ads, Miami (positive Spanish 209, negative Spanish 107, positive General 1637, negative General 2375, Mixed General 2387). If we set the ad measures to these values, the probability of turnout is 83.7 percent, which is similar to what it was in the Los Angeles and Chicago markets. If we set the demobilizing ads to zero, then the probability of turnout increases to 99.9 percent. An examination of ads aired at the media market level points to the wide range of strategies at work.

The discussion above illustrates that an understanding of how different communication strategies work in tandem can allow for a more efficient and effective allocation of resources in future campaigns. For example, Tampa was subject to a saturation of general ads (over 6000) and the probability 
of turnout given the number of ads in Tampa is 97.9 percent. While this probability is high, the campaigns also spent a great deal of money on ads. Meanwhile, Los Angeles saw a high number of Spanish ads and few general ads and the probability of turnout is 83.8 percent. If the harmful negative/mixed Spanish and mixed general ads are removed, then the probability of turnout surpasses that of Tampa. Our results suggest that campaigns can get more bang for their buck with Latinos by airing positive segmented ads compared to the non-segmented ads. In other words, the brute force of quantity may bring about the desired mobilization effect, but a more precise understanding of different ad types may allow for more efficient campaign outreach among a targeted group.

\section{DISCUSSION AND CONCLUSION}

Our paper has shed light on the question of whether the efforts at mobilization made by the presidential campaigns in 2000 got through to the Latino electorate. More generally, our analysis considered the effectiveness of a segmented campaign strategy, which consists of both direct and indirect contact. In this section, we will first review the support for our key hypotheses. We will then turn to a discussion of some of the limitations of our study, and conclude by looking forward to avenues for future research on this topic.

We found strong support for the importance of a mix of mobilization strategies in increasing the likelihood of turnout among a key demographic segment of the electorate: registered Latino citizens. Building on integrated marketing communications (IMC), we offered a theory of market segmentation to better understand the political mobilization of Latinos in 2000. Strategies of IMC hold that consumers, or voters, are exposed to multiple communications campaigns which as a whole seek to convey a message. However, certain approaches are seen to more directly or forcefully convey a core message-vote! In this paper we focused on the comparative strength of direct mobilization vis-à-vis indirect mobilization and an approach that segmented the electorate for maximum effectiveness in the delivery of the campaign message.

We found that both direct contact and exposure to political ads had a mobilizing effect. Also as expected, we found that direct forms of mobilization are more effective than indirect forms of mobilization. The strongest support for segmentation came with respect to direct contact, in which contact by a Latino had a positive significant effect while non-Latino contact had no effect at all. With respect to political ads, we also found strong support for the segmentation hypothesis with positive Spanish ads having the greatest mobilizing effect.

We recognize that there are several limitations to our analysis. First, the data are limited to just five states and to registered Latinos in the 2000 election. 
Expanding the data to include a nationally representative sample of eligible Latino citizens would allow for a broader consideration of the effects of outreach on a variety of turnout propensities and, more specifically, provide data for additional markets such as Albuquerque and Las Vegas, which witnessed extensive Spanish-language political ads. Second, related to our findings, negative/mixed Spanish ads had a demobilizing effect while negative English ads were mobilizing. Because campaigns are newer to Spanish advertising, it could be that their negative ads are less sophisticated than similar ads in English, or it could be that Latinos who primarily watch Spanish-language TV do not like negative/mixed ads, while Latinos who primarily watch English-language TV are mobilized in response to negative ads. This is a topic to explore in future research, perhaps with controlled experiments exposing Latino voters to a variety of positive and negative ads. Third, the imperfect measures of direct and indirect contact mean that we have to interpret the results with some caution. The stark differences apparent between direct Latino contact and the ad measures may partly be a function of measurement error. Again, these limitations may be best addressed in future work using controlled experiments in which exposure to both types of appeals can be tracked. A final consideration to include in future research is how other groups react to targeted appeals, or how individuals react to segmented communication geared toward others.

Overall, the results have important implications for future mobilization efforts. First, it does appear that an integrated strategy of direct and indirect contact is important for increasing the likelihood of turnout. However, to be most effective, campaigns may want to segment their communication to specific groups with more nuanced messages. In our estimates, airing 27 positive Spanish ads had the same effect as being directly contacted by a Latino. Whether or not direct or indirect segmented communication is the best strategy will depend in part on the costs associated with each. The successful implementation of an IMC appears to be a work in progress, at least among the Latinos, and the calibration of direct versus indirect communication remains to be perfected. Given the recent efforts of targeting this population through multiple modes, this outcome is understandable. It remains to be seen whether the current parties can create more effective group-targeted appeals in future elections, and how they will balance the mix of direct versus indirect contact among various segments of the American electorate.

\section{NOTES}

1. Ramírez (2007) argues that the effects of phone calls on turnout may vary depending on whether an individual is a likely voter and the political context. He developed a quasi-experimental design using data from a phone call effort targeting less likely Latino voter precincts by NALEO in Los Angeles and found that native born Latinos and those registered prior to the politically charged environment of the 1990s (1994) were affected by the mobilization effort. 
2. The data was obtained from a joint project of the Brennan Center for Justice at New York University School of Law and Professor Kenneth Goldstein of the University of Wisconsin-Madison, and included media tracking data from the Campaign Media Analysis Group in Washington, D.C. The Brennan Center-Wisconsin project was sponsored by a grant from the Pew Charitable Trusts. The opinions expressed in this article are those of the author and do not necessarily reflect the views of the Brennan Center, Professor Goldstein or the Pew Charitable trust.

3. The total number of ads aired in each market was collapsed because the TRPI survey was not conducted throughout the campaign, preventing us from generating a measure taking into account the date of interview (Gilens, Vavreck, and Cohen 2007).

4. This is admittedly an imperfect measure, but as Goldstein and Freedman (2002) point out, a perfect measure is impossible to attain given that even if ad viewing is known, whether or not the respondent was attentive is unknown. It also is an improvement over self-reported recall of ads (see Ansolabehere, Iyengar, and Simon, 1999).

5. Another method for approximating exposure is to use cost per household of airing a political advertisement (Abrajano, 2010).

6. We do not differentiate the sponsoring party in that we would need to include an additional four dummy variables, and we wanted to try to keep the model as parsimonious as possible.

7. Missing values on the continuous measures were recoded to the mean.

8. We did have models with homeownership and female, but the p-values were very high so we did not include them. Their inclusion does not change the results for the key variables of interest.

9. Because our hypotheses are uni-directional - that is, we expect an increase in turnout - we can rely on a one-tailed test of significance.

10. We recognize that a hierarchical non-linear model might be appropriate. However, given our relatively small $n$ of media markets (13), we were reluctant to use a hierarchical model. That being said, the results are consistent using a hierarchical non-linear model. The only difference is that the p-values for negative and mixed ads are a bit higher but still significant $(\mathrm{p}<.10$, one-tailed).

11. We did find some evidence of endogeneity for the two contact measures, but not the ads. We could not find valid instruments to estimate a three stage regression. Without valid instruments, 2SLS is biased toward the OLS estimate; thus, we stick to our original analyses. We also estimated this using the Gigli Fixed Effects Bayesian Ratio Calculator, for Window 95 (Nicholson, 2003), and the results were consistent.

12. As another indicator of the improvement of Model 2 over Model 1, we predicted turnout by media market for each model and compared this to the actual turnout in the media market for the sample. The model with ads comes closer to predicting the actual turnout rate of individuals in our sample for 10 out of the 13 media markets. The only media markets in which Model 2 performs worse than Model 1 is for Austin, San Diego, and Sacramento. None of these markets were competitive, so individuals in these markets were not exposed to many ads.

13. While we do not focus on this in the paper, we did also explore the combined effect of ads and contact by splitting the sample among those contacted and non-contacted. We found similar effects for the ads among those who were not contacted and null effects for those who were contacted. These latter results should be interpreted with caution since we had a small sample.

14. Among the markets that aired positive Spanish language ads, only New York did not reach the 27 ad threshold. In Los Angeles, 292 positive Spanish ads aired, in Miami 209, in San Diego 137, in Fresno 102, in Sacramento 77, in Chicago 36, and in New York only 3.

\section{REFERENCES}

Abrajano Marisa, A. (2010). Campaigning to the new American electorate: Advertising to Latino voters. Palo Alto, CA: Stanford University Press.

Abrajano, M., J. Cortina, and R. O. de la Garza. (2008). Get me to the polls on time: Mobilization and Latino turnout in the 2000 election. In Jane Junn and Kerry L. Haynie (Eds.), Race, immigration and politics. Cambridge: Cambridge University Press.

Abrajano, M. A. and C. Panagopoulos. (2009). Targeting Latino voters with Spanish vs. English language appeals: Field experimental evidence. Paper presented at 
the 2009 American Political Science Association annual conference, Toronto, ON, CA.

Arceneaux, K. and D. Nickerson. (2009). Who is mobilized to vote? A re-analysis of 11 field experiments. American Journal of Political Science, 53(1), 1-16.

Ansolabehere, Stephen and Shanto Iyengar. (1995). Going negative: How political advertisements shrink and polarize the electorate. New York: The Free Press.

Ansolabehere, S., S. Iyengar, A. Simon, and N. Valentino. (1994). Does attack advertising demobolize the electorate?. American Political Science Review, 88(4), 829-838.

Ansolabehere, S., S. Iyengar, and A. Simon. (1999). Replicating experiments using aggregate and survey data: The case of negative advertising and turnout. American Political Science Review, 93(4), 901-909.

Barreto, M. A. (2007). ¡Sí se puede! Latino candidates and the mobilization of Latino voters. American Political Science Review, 101(3), 425-441.

Barreto, M. and S. Nuño. (2011, June). The effectiveness of co-ethnic contact on Latino political recruitment. Political Research Quarterly, 64, 448-459.

Batra, Rajeev J., John G. Myers, and David A. Aaker. (1996). Advertising management, 5th ed. Englewood Cliffs, NJ: Prentice Hall.

Beck, P. A. and M. K. Jennings. (1982). Pathways to participation, American Political Science Review, 76, 94-108.

Campbell, Angus, Phillip Converse, Warren Miller, and Donald Stokes. (1960). The American voter. New York: Wiley.

Clinton, J. D. and J. S. Lapinski. (2004). "Targeted" advertising and voter turnout: An experimental study of the 2000 presidential election. Journal of Politics, 66(1), 69-96.

DeFrancesco Soto, V. and J. Merolla. (2006). Vota por tu futuro: Partisan mobilization in the 2000 presidential election. Political Behavior, 28(4), 285-304.

DeSipio, Louis. (1996). Counting on the Latino vote: Latinos as a new electorate. Charlottesville, VA: University of Virginia Press.

Finkel, S. E. and J. G. Geer. (1998). A spot check: Casting doubt on the demobilizing effect of attack advertising. American Journal of Political Science, 42(2), 573-595.

Freedman, P. and K. Goldstein. (1999). Measuring media exposure and the effects of negative campaign ads. American Journal of Political Science, 43(4), 1189-1208.

Geer, John G. (2006). In defense of negativity: Attack ads in presidential campaigns. Chicago: University of Chicago Press.

Gerber, A. S. and D. P. Green. (2000). The effect of a nonpartisan get-out-the-vote drive: An experimental study of leafletting. Journal of Politics, 62(3), 846-857.

Gerber, Alan S. and Donald P. Green. (2008). Get out the vote: How to increase voter turnout, 2nd ed. Washington, DC: Brookings Institution Press.

Gerber, A. S., D. P. Green, and M. Green. (2003). Partisan mail and voter turnout: Results from randomized field experiments, Electoral Studies, 22, 563-579.

Gilens, M., L. Vavreck, and M. Cohen. (2007). See spot run: The rise of advertising, the decline of news and the American public's perceptions of presidential candidates. Journal of Politics, 69(4), 1160.

Goldstein, K. and P. Freedman. (2002). Campaign advertising and voter turnout: New evidence for a stimulation effect. The Journal of Politics, 64(3), 721-740. 
Goldstein, K. M. and T. N. Ridout. (2002). The politics of participation: Mobilization and turnout over time. Political Behavior, 24(1), 3-29.

Gosnell, Harold F. (1927). Getting out the vote: An experiment in the stimulation of voting. Chicago: University of Chicago Press.

Green, D., A. Gerber, D. Nickerson. (2008). Getting out the vote in local elections: Results from six door-to-door canvassing experiments. The Journal of Politics, 65(4), 1083-1096.

Green, D. P. and L. Vavreck. (2008). Analysis of cluster-randomized field experiments: A comparison of alternative estimation approaches, Political Analysis, 16, 138-162.

Ha, S. and D. Karlan. (2009). Get-out-the-vote phone calls: Does quality matter?" American Politics Research, 37(2), 353-369.

Holbrook, T. and S. McClurg. (2005). The mobilization of core supporters: Campaigns, turnout, and electoral composition in United States presidential elections. American Journal of Political Science, 49(4), 689-703.

Jackman, R. W. (1987). Political institutions and voter turnout in the industrialized democracies. American Political Science Review, 81(2), 405-424.

Jackson, R. and T. Carsey. (2007). US Senate campaigns, negative advertising, and voter mobilization in the 1998 midterm election. Electoral Studies, 26(1), 180-195.

John, P. and T. Brannan. (2008). How different are telephone and canvassing? Results from a "get out the vote" field experiment in the British 2005 general election. British Journal of Political Science, 38(3), 565-574.

Kim, I., D. Han, and D. E. Schultz. (2004). Understanding the diffusion of integrated marketing communications. Journal of Advertising Research, 44(1), 31-45.

Kitchen, P. J. (2005). New paradigm-IMC-under fire. Competetiveness Review, 15(1), 72-80.

Kitchen, P. J. and D. E. Schultz. (1999). A multi-country comparison of the drive for IMC. Journal of Advertising Research, 39(1), 21-38.

Leighley, Janet. E. (2001). Strength in numbers? The political mobilization of racial and ethnic minorities. Princeton, NJ: Princeton University Press.

Leighley, J. E. and J. Nagler. (1992). Individual and systematic influences on turnout: Who votes? 1984. Journal of Politics, 54(3), 718-738.

Leighley, J. E. and A. Vedlitz. (1999). Race, ethnicity and political participation: Competing models and contrasting explanations. The Journal of Politics, 61(4), 1092-1114.

McNulty, J. E. (2005). Phone-based GOTV: What's on the line? Field experiments with varied partisan components, 2002-2003. Annals of Political and Social Science, 601(1), 85-101.

Michelson, M. (2003). Getting out the Latino vote: How door-to-door canvassing influences voter turnout in rural central California. Political Behavior, 25(3), $247-263$.

Michelson, M. (2005). Meeting the challenge of Latino voter mobilization. Annals of Political and Social Science, 601(1), 85-101.

Michelson, M., L. Garcia-Bedolla, and D. P. Green. (2007). New experiments in minority voter mobilization: A report on the California votes initiative. Insight, $3-42$. 
Nicholson, S. P. (2003). GIGLI: Fixed effects bayesian estimator for Windows 95. Version 2.0. Atlanta, GA: Georgia State University, August, 1.

Nickerson, D. W., R. D. Friedrich, and D. C. King. (2006). Partisan mobilization campaigns in the field: Results from a statewide turnout experiment in Michigan. Political Research Quarterly, 59(1), 85-97.

Nickerson, D. (2007a). The ineffectiveness of e-vites to democracy. Social Science Computer Review, 25(4), 494-503.

Nickerson, D. (2007b). Quality is job one: Professional and volunteer voter mobilization calls. American Journal of Political Science, 51(2), 269-282.

Nickerson, D. (2008). Is voting contagious? Evidence from two field experiments. American Political Science Review, 102(1), 49-57.

Nuño, S. (2007). Latino mobilization and vote choice in the 2000 presidential election. American Politics Research, 35(2), 273-293.

Panagopoulos, C. and D. Green. (2008a). Testing the impact of radio advertisements on electoral competition. American Journal of Political Science, 52(1), 156-168.

Panagopoulos, C. and D. Green. (2008b). Spanish-language radio advertisements and Latino voter turnout in the 2006 congressional elections: Field experimental evidence. Paper presented at the 2008 Annual Meeting of the Midwest Political Science Association.

Panagopoulos, C. (2009a). Partisan and nonpartisan message content and voter mobilization. Political Research Quarterly, 62(1), 70-76.

Panagopoulos, C. (2009b). Street fight: The impact of a street sign campaign on voter turnout. Electoral Studies, 28(2), 309-313.

Pantoja, A. D. and N. D. Woods. (2000). Turning out the Latino vote in Los Angeles County: Did interest group efforts matter?, American Review of Politics, 20, 141-162.

Petty, R. E. and J. T. Cacioppo. (1986). Communication and persuasion: Central and peripheral routes to attitude change. New York: Springer-Verlag.

Ramirez, R. (2002). Getting out the vote: The impact of non-partisan voter mobilization efforts in low turnout Latino precincts. Paper presented at the Annual Meeting of the American Political Science Association.

Ramirez, R. (2005). Giving voice to Latino voters: A field experiment on the effectiveness of a national nonpartisan mobilization effort. Annals of Political and Social Science, 601(1), 41-65.

Ramirez, R. (2007). Segmented mobilization: Latino nonpartisan get-out-the-vote efforts in the 2000 general election. American Politics Research, 35(2), 155-75.

Rosenstone, S. J. and J. M. Hansen. (1993). Mobilization, participation, and democracy in America. New York: Macmillan.

Schultz, D. E. (1991). Integrated marketing communications: The status of integrated marketing communications programs in the US today. Journal of Promotion Management, 1(1), 99-104.

Segal, Adam. (2003). The Hispanic priority: The Spanish language television battle for the Hispanic vote in the 2000 U.S. presidential election. Hispanic Voter Project Report. Baltimore: Johns Hopkins University.

Shaw, D., R. O. de la Garza, and J. Lee. (2000). Explaining Latino turnout in 1966: A three-state, validated survey approach, American Journal of Political Science, 44, 332-340. 
Subervi-Velez, F. (ed). (2008). The mass media and Latino politics: Studies of media content, campaign strategies and survey research 1984-2004. New York: Routledge.

Vavreck, L. (2007). The exaggerated effects of advertising on turnout: The dangers of self-reports. Quarterly Journal of Political Science, 2(4), 325-343.

Wattenberg, M. and C. L. Brians. (1999). Negative campaign advertising: Demobilizer or mobilizer?. American Political Science Review, 93(4), 891-899.

Wolfinger, Raymond. and Steven J. Rosenstone. (1980). Who Votes? New Haven: Yale University Press.

Wong, J. (2005). Mobilizing Asian American voters: A field experiment, The Annals of the American Academy of Political and Social Science, 601, 102-114.

\section{AUTHOR NOTES}

Matt A. Barreto is Associate Professor of Political Science and Director of the Washington Institute for the Study of Ethnicity \& Race (WISER) at the University of Washington, Seattle. He is a founding partner of Latino Decisions, a polling firm that focuses on Latino voter attitudes and behavior. His research focuses on Latino and immigrant political participation, and campaign mobilization.

Jennifer Merolla is Associate Professor and Chair in the Department of Politics and Policy at Claremont Graduate University. Her research focuses on how the political environment shapes individual behavior across many areas of study such as threat, voting behavior, parties, public opinion, race and ethnic politics, women and politics, and religion and politics. Her work has appeared in journals such as Electoral Studies, Journal of Politics, Political Behavior, Political Psychology, and Women, Politics, and Policy. She is co-author of Democracy at Risk: How Terrorist Threats Affect the Public, published by the University of Chicago Press (2009).

Victoria DeFrancesco Soto's work focuses on campaigns and elections underpinned by the intersection of political psychology and race and ethnic politics. She is interested in how cognition and affect shape the processing of political information within a dynamic political environment of changing racial and ethnic demographics. Her research projects examine the influence of social group identity on political behavior, in particular with regards to campaigns, black-Latino intergroup relations, comparative race studies, and attitudes toward immigration. She is currently a visiting fellow at the University of Texas, and Director of Communications for Latino Decisions. 